\title{
Microscopic analysis of the alkali-silica reactivity of various origin fine aggregate
}

\author{
Aneta Antolik ${ }^{1, *}$, Daria Jóźwiak-Niedźwiedzka ${ }^{1}$, Kinga Dziedzic ${ }^{1}$, Karolina Bogusz ${ }^{1}$, \\ and Michat A. Glinicki ${ }^{1}$ \\ ${ }^{1}$ Institute of Fundamental Technological Research, Polish Academy of Sciences, Pawińskiego 5B, \\ 02-106 Warsaw, Poland
}

\begin{abstract}
Alkali silica reaction (ASR) is a harmful phenomenon occurring as a result of chemical interactions between sodium and potassium hydroxides in the pore solution and reactive minerals contained in the aggregate. Reactive minerals like microcrystalline, cryptocrystalline or strained quartz dissolve in the alkaline solution and form an expansive gel product. Proper selection of concrete constituents is necessary to ensure the durability of concrete structures. The proper recognition of the aggregate mineralogical composition is a very important element in the process of selection of concrete components due to the risk of ASR occurrence. This paper presents the results of detailed microscopic analysis of alkali-silica reactivity of domestic fine aggregates of various origins. Six siliceous sands from different locations in Poland and one limestone sand were tested. Detailed petrographic analysis was performed on thin sections. In all siliceous sands micro- and cryptocrystalline quartz was recognized as a reactive mineral. Digital image analysis was performed for quantitative assessment of the potential of reactivity of sands. It revealed, that siliceous river sands were the most susceptible to an alkali-silica reaction, which was confirmed by mortar bar expansion test performed according to the standard test method.
\end{abstract}

\section{Introduction}

The issue of alkali-silica reaction (ASR) is known and discussed by scientists around the world. A recent summary concerning this phenomenon, presented by Rajabipour et. al [1] and Figueira et al. [2], concluded that the phenomenon was not fully recognized. The severity of this phenomenon is associated with the inability to stop it when it appears in a concrete structure. An internal destruction will continue over time, which may necessitate major repair, partial or full demolition, which generate huge costs. Proper selection of concrete constituents is a key issue in preventing the occurrence of an alkali-silica reaction, especially in structures such as road pavements and bridges, which must be durable for several dozen years [3].

The occurrence of ASR is influenced by three main factors: high humidity, availability of alkali and presence of reactive minerals in aggregate [4]. When designing the concrete

\footnotetext{
*Corresponding author: aantolik@ippt.pan.pl
} 
composition, we are able to have an influence on the alkali content in cement and the proper choice of aggregate that will not contain hazardous minerals. However, due to the climatic conditions in Poland and the related need to use de-icing agents which could be an external source of alkali, the use of low-alkali cement does not protect the structure from damage [5]. Therefore, it is extremely important to identify the presence of reactive minerals in aggregate and the potential alkali-silica reactivity to minimize ASR risk as much as possible.

Crushed rock aggregate is considered to be homogeneous in terms of mineral composition, physical and mechanical properties, while a natural fine aggregate is usually inhomogeneous. Studies on the reactivity of fine aggregate were conducted, however, however, the ability to unquestionably determine the potential for ASR still remains a challenge. Sanchez et al. [6] analyzed an influence of fine (up to $5 \mathrm{~mm}$ ) and coarse aggregate on the alkali-silica reaction in concrete. They found that the durability of concrete with respect to ASR was more influenced by fine aggregate compared to coarse aggregate. Problems related to the reactivity of fine aggregate were described by Lukschowa et al [7]. They suggested the simultaneous use of several methods of testing for potential of alkaline reactivity, since one may be ineffective. They also highlighted the benefits of quantitative analysis of petrographic images. Results of petrographic analysis on thin sections made from different Polish aggregates were presented in [8], including these from glacial deposits. Such evaluation of the mineral composition of aggregates enabled preliminary classification of aggregate into one of the three classes of reactivity according to RILEM. Naziemiec [9] presented diversity of Polish fine aggregates in relation to their alkali-silica potential. However, he did not get clear results, both non-reactive and highly reactive sands were recognized.

The objective of this investigation was to characterize the alkali-silica reactivity of sands from various locations in Poland by quantitative microscopic analysis. The digital image analysis of minerals and microstructural features enabled a comparison of results with mortar bar expansion according to accelerated mortar-bars test at $80^{\circ} \mathrm{C}$ in $1 \mathrm{M} \mathrm{NaOH}$ solution.

\section{Materials and laboratory test methods}

\subsection{Materials}

Six different natural siliceous sands (S1-S6) and one limestone sand (L) from Poland were used. Two sands were river origin (S1 and S2), four sands were fossils origin (S3-S6):

- $\mathrm{S} 1$ - river sand

- $\mathrm{S} 2$ - river sand

- S3 - fossil sand

- S4 - fossil sand

- S5 - fossil sand

- S6 - fossil sand

- L - limestone crushed sand

The selection criterion was widespread use and availability of fine aggregate in Poland. The sands used were the same as those nowadays used for roads construction. Siliceous sands were located in Pleicstocene deposits and crushed limestone sand in Devonian, both from central Poland.

The verification of microscopic diagnosis was carried out by accelerated mortar-bar tests. For this test Portland cement CEM I 42.5R with the alkali content of $0.88 \% \mathrm{Na}_{2} \mathrm{O}_{\text {eq }}$ was used. The detailed chemical composition of cement is presented in Table 1. 
Table 1. Chemical composition of cement, XRF method, wt \%.

\begin{tabular}{|c|c|c|c|c|c|c|c|c|c|}
\hline Constituent & $\mathrm{SiO}_{2}$ & $\mathrm{Al}_{2} \mathrm{O}_{3}$ & $\mathrm{Fe}_{2} \mathrm{O}_{3}$ & $\mathrm{CaO}$ & $\mathrm{MgO}$ & $\mathrm{SO}_{3}$ & $\mathrm{Na}_{2} \mathrm{O}$ & $\mathrm{K}_{2} \mathrm{O}$ & $\mathrm{Na}_{2} \mathrm{O}_{\text {eq }}$ \\
\hline $\begin{array}{c}\text { Cement } \\
\text { CEM I 42.5 R }\end{array}$ & 19.42 & 5.45 & 2.94 & 64.10 & 1.75 & 3.50 & 0.24 & 0.97 & 0.88 \\
\hline
\end{tabular}

\subsection{Testing methods}

Microscopic investigations were made on thin sections prepared by using PELCON equipment. Fine aggregate grains, after pre-treatment with fluorescent epoxy resin were polished to a thickness of about $20 \pm 2 \mu \mathrm{m}$. Each thin section contained about 300 grains. Detailed characterization of mineral composition of tested sands was conducted with OLYMPUS BX51 petrographic microscope. Equipping the microscope with an automatic moving table and a DP25 digital color camera made it possible to collect the image from the entire surface of the thin section. The individual images were then stitched in one image using Image Composite Editor software. Digital image analysis was performed by Image Pro Plus software. Observations on an optical microscope were carried out in transmitted and crosspolarized light. Additionally, gypsum plate was applied for better recognition of reactive components of aggregate. A quantitative analysis of the content of reactive minerals in fine aggregate has been carried. Stitched images of thin sections were analysed. The procedure of digital analysis of quartz content is shown in Fig. 1. The first step was to cut off the background (resin) based on its color. Then, based on the experimenter's experience, reactive quartz grains were selected. A similar procedure was applied for quantitative analysis of content of limestone grains in tested sands.

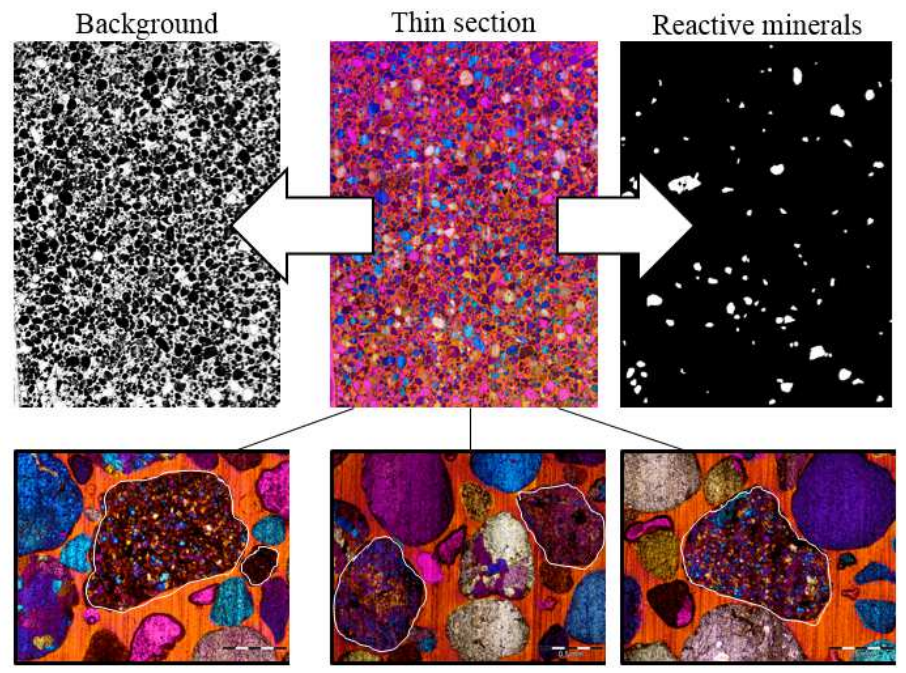

Fig.1. Digital image analysis procedure of the reactive minerals (micro- and cryptocrystalline quartz) estimation

Verification of the aggregate reactivity determined by quantitative petrographic analysis was carried out using the accelerated mortar-bar tests, according to ASTM C1260 [10] standard, RILEM AAR-2 [11] and Polish Technical Guidelines [12] method. Mortar-bars were exposed in $1 \mathrm{~N} \mathrm{NaOH}$ solution in $80^{\circ} \mathrm{C}$, and the elongation was measured systematically. $0.15 \%$ of expansion limit after 14 days of exposition was applied. To check the trend of expansion (or extinction), the study was extended to 28 days. Fine aggregate was tested as supplied from the producer. Although fine sand fractions, below $63 \mu \mathrm{m}$ can cause a 
pozzolanic reaction and reduce expansion $[13,14]$, the sands were not sieved in order to replicate a standard practice of using these materials for road construction in Poland.

Mortar-bars after accelerated tests were cut, grinded and polished and sputtered with carbon for Scanning Electron Microscope investigation. Specimens were tested on a Zeiss sigma VP microscope equipped with Energy Dispersive X-Ray detector (EDX), in the backscatter mode using an acceleration voltage of $20 \mathrm{kV}$.

\section{Results and discussion}

Petrographic analysis was focused in identification of the reactive minerals in fine aggregate, Fig 2. Particular attention was paid to the size of the quartz crystals.

In all siliceous sands differents amouts of micro- and cryptocrystalline quartz were found. A higher content of reactive quartz was found in the river sands. The following relationship was found: the higher the content of reactive quartz, the lower the content of limestone grains. Results of digital image analysis are presented in Table 2.

For comparison with microscopic investigation of potential of alkali-silica reactivity of fine aggregate, the accelerated mortar-bar tests were performed. Results are presented in Fig. 3. and Table 2.

Polish Technical Guidelines PB/1/18 [12] were used to assess the silica reactivity of fine aggregate according to the accelerated method. According to Guidelines, for natural sands expansion limit is $0.15 \%$. The expansion above the limit was demonstrated by both river sands. All fossil sands showed expansion below the limit. However, extending the test time to 28 days showed that expansion in almost all siliceous sands maintained the growth trend (no rate decrease was observed). The lowest expansion was obtained for limestone sand.

Table 2. Content of reactive quartz and limestone grains in tested sands.

\begin{tabular}{|c|c|c|c|c|}
\hline Name & $\begin{array}{c}\text { Sand } \\
\text { origin }\end{array}$ & $\begin{array}{c}\text { Content of micro- and } \\
\text { cryptocrystalline quartz } \\
{[\%]}\end{array}$ & $\begin{array}{c}\text { Content of } \\
\text { limestone grains } \\
{[\%]}\end{array}$ & $\begin{array}{c}\text { Expansion after } \\
\mathbf{1 4} \text { days } \\
\mathbf{( 0 . 1 5 \%} \text { limit })\end{array}$ \\
\hline S1 & River & 5.20 & 0.10 & 0.32 \\
\hline S2 & River & 3.68 & 0.33 & 0.30 \\
\hline S3 & Fossil & 2.22 & 1.50 & 0.14 \\
\hline S4 & Fossil & 1.89 & 7.32 & 0.08 \\
\hline S5 & Fossil & 1.33 & 13.70 & 0.04 \\
\hline S6 & Fossil & 1.26 & 4.62 & 0.12 \\
\hline L & Crushed & 0.10 & 96.00 & 0.01 \\
\hline
\end{tabular}



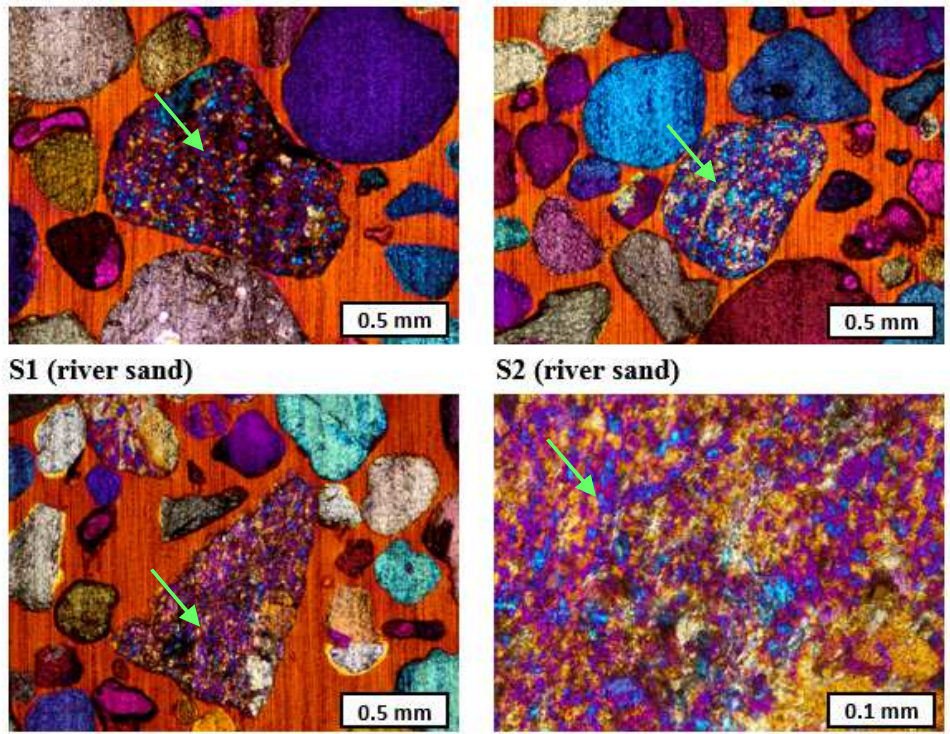

S4 (fossil sand)

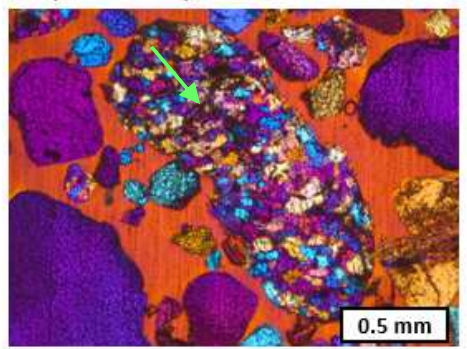

S4 (fossil sand)
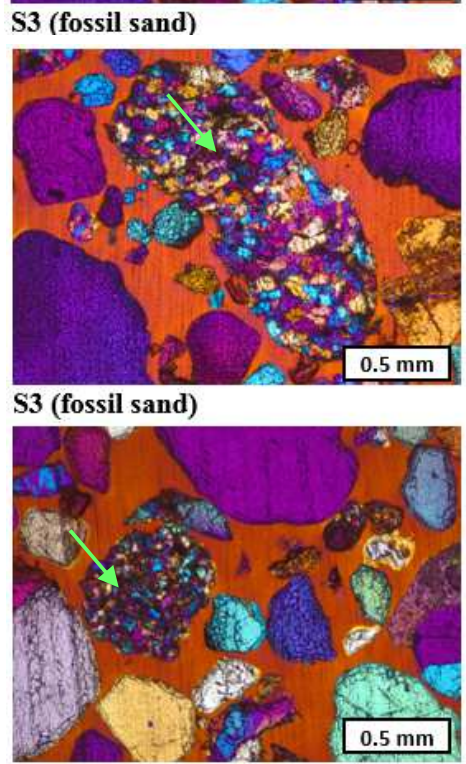

S6 (fossil sand)

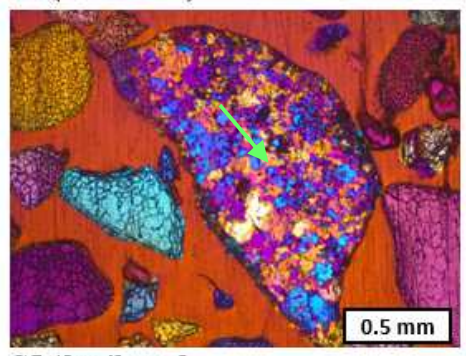

\section{S5 (fossil sand}

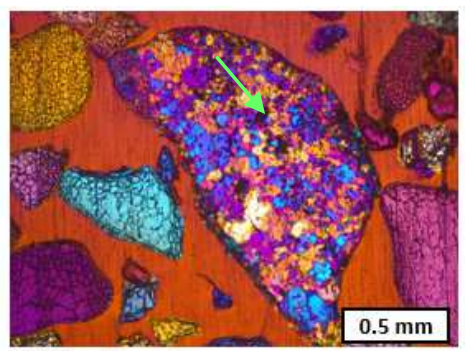

\section{S5 (fossil sand}

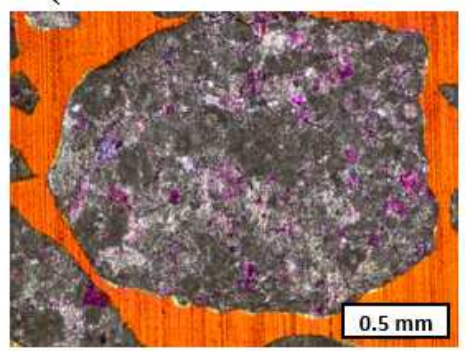

\section{L (crushed sand)}

Fig. 2. Images from thin sections of micro- and cryptocrystalline form of quartz (S1, S2, S4) and limestone grains $(\mathrm{L})$. 


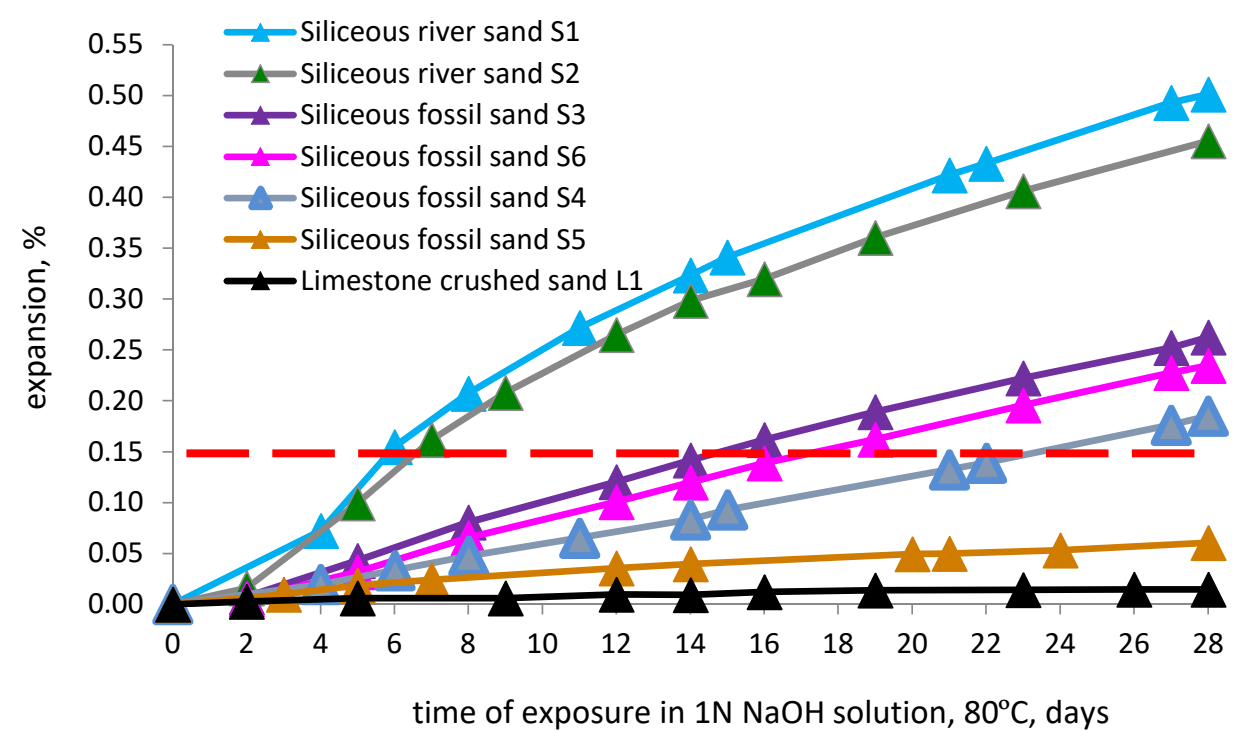

Fig. 3. Expansion of mortar-bars exposed in $1 \mathrm{~N} \mathrm{NaOH}$ solution in $80^{\circ} \mathrm{C}$ for 28 days.

The results of mortar-bar expansion confirmed the digital image analysis results concerning the micro- and cryptocrystalline quartz. The relationship between quantitative image analysis and expansion in accelerated mortar-bar tests is presented in Fig. 4. The highest expansion was observed in sand with the highest amount of micro- and cryptocrystalline quartz and the lowest content of limestone grains.

The obtained results are consistent with literature data, [15, 16]. Wigum et al. [15] revealed that porous flint and opal present in sand fraction were the reason of the concrete degradation due to ASR. Pedersen et. al. [16] showed that almost 90\% of all cases with ASR-damaged concrete structures were caused by porous opaline or calcareous opaline flint in the sand fraction. Jóźwiak-Niedźwiedzka et al. [17] also confirmed the effectiveness of image analysis to assess the potential for ASR in aggregate.

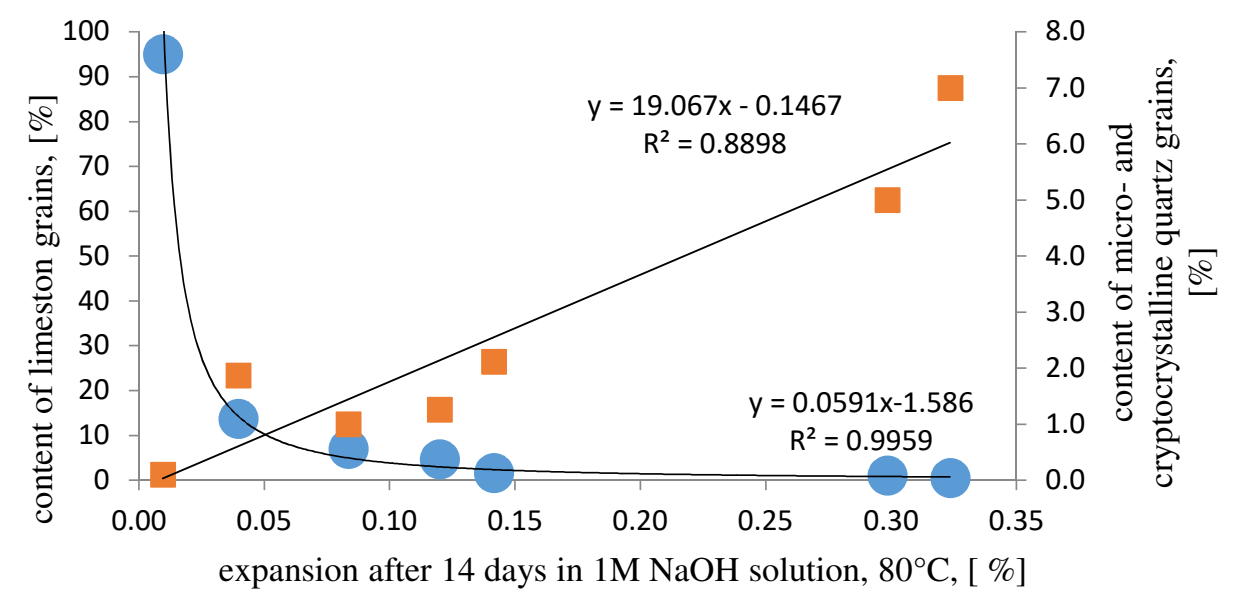

Fig. 4. The relationship between expansion of mortars in accelerated mortar-bar tests and: content of micro- and cryptocrystalline quartz grains (squares); content of limestone grains (circles). 

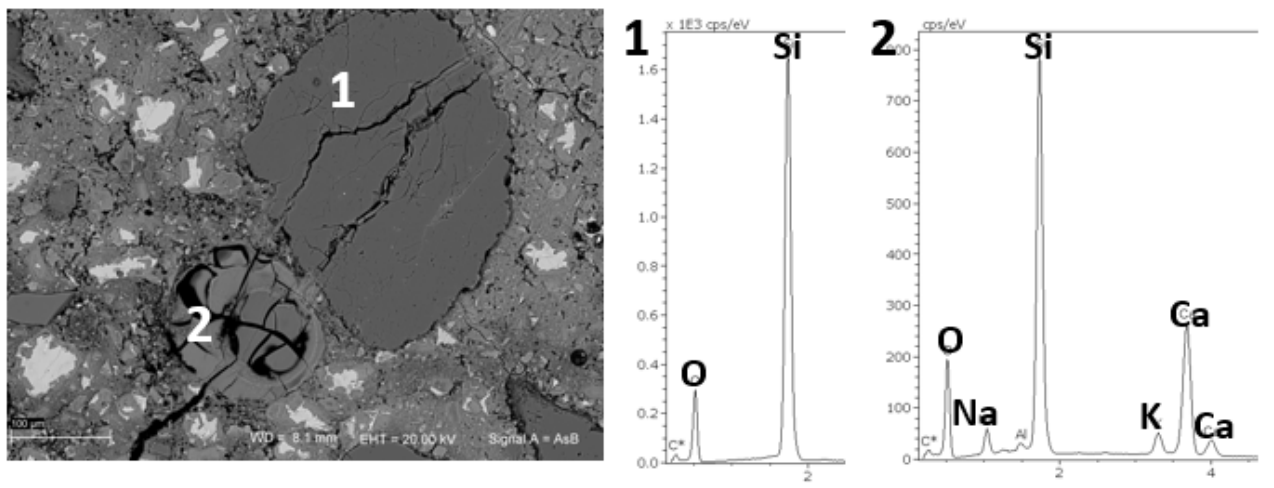

Fig. 5. SEM image of mortar with siliceous sand after accelerated mortar-bar test with reactive quartz grain and air void filled with $\mathrm{Si}-\mathrm{Ca}-\mathrm{Na}-\mathrm{K}$ gel in $\mathrm{S} 1$ sand.

Mortar-bars after accelerated tests were observed on SEM with EDS. In Fig. 5 the image of cracked grain of quartz together with the results of the analysis of the composition in microareas are presented. Both the quartz grain and the cement matrix are cracked. The cracks are filled with Si-Ca-Na-K gel. The expansive gel formed in the aggregate migrated into the cement matrix, causing cracking and filling the air voids. The ASR product is highly expansive, which is the main reason for the elongation of mortar bars.

\section{Conclusions}

From the conducted research, the following conclusions can be drawn:

- The investigation has shown that fine aggregate were different in potential for alkali-silica reaction depending on their origin (river, fossil).

- The tested sands were characterized by various contents of reactive form of quartz (microand crypto-crystalline) and limestone grains.

- The highest content of micro- and cryptocrystalline quartz was found in river sands and the lowest in limestone sand.

- River sands had expansion in an accelerated mortar-bar tests above the limit after 14 days. Fossil sands had expansion below the limit after 14 days, but extending the test to 28 days does not cause extinction, the trend is still upward.

- Quantitative image analysis of content of reactive minerals and limestone grains in tested sand correspond to expansion in accelerated mortar-bar tests. The higher content of reactive quartz and the lowest content of limestone grains, the higher expansion of mortar bars.

- ASR gel detection by SEM analysis confirmed that the expansion was due to alkali-silica reaction.

- Digital image analysis of aggregate mineral composition on thin sections allowed for prequalification of fine aggregate suitability for ASR-free concrete.

This paper has been prepared as a part of the Project "Alkali-Aggregate Reactivity of Domestic Aggregates" financed by the National Centre for Research and Development (NCBiR) and the General Directorate for National Roads and Motorways (GDDKiA) in Poland within 2016-2019. 


\section{References}

1. F. Rajabipour, E. Giannini, C. Dunant, et al, Cem. Concr. Res. 76, 130-146 (2015)

2. R. B. Figueira, R. Sousa, L. Coelho, et al, Constr. Build. Mater. 222, 903-931 (2019)

3. D. Jóźwiak-Niedźwiedzka, A. Antolik, K. Dziedzic, M. A. Glinicki, K. Gibas, Roads and Bridges 18, 67-83 (2019)

4. I. Fernandes, M. A .T. M. Broekmans, Metallogr. Microstruct. Anal. 2, 257-267 (2013)

5. P. R. Rangaraju, K. Sompura, J. Desai, J. Olek, Airfield and Highway Pavements, 486497 (2006)

6. L. F. M. Sanchez, B. Fournier, M. Jolin, et al, Cem. Concr. Res. 93, 17-31 (2017)

7. Š. Lukschová, R. Přikryl, Z. Pertold, Mag. Concr. Res. 61, 645-654 (2009)

8. D. Jóźwiak-Niedźwiedzka, K. Gibas, M. A. Glinicki, Roads and Bridges 16, 223-239 (2017)

9. Z. Naziemiec, Roads and Bridges 17, 271-283 (2018)

10. ASTM C 1260-14, American Society for Testing and Materials, Standard Test Method for Potential Alkali Reactivity of Aggregates (Mortar-Bar Method), (Annual Book of ASTM Standards, Vol. 04.02, Philadelphia, 2014)

11. RILEM Recommended Test Method: AAR-2-Detection of Potential Alkali-Reactivity - Accelerated Mortar-Bar Test Method for Aggregates (in RILEM Recommendations for the Prevention of Damage by Alkali-Aggregate Reactions in New Concrete Structures, Eds. P. J. Nixon, I. Sims, Springer Netherlands, 61-77, 2016)

12. A. Garbacik, M.A. Glinicki, D. Jóźwiak-Niedźwiedzka, G. Adamski, K. Gibas, Technical guidelines for the classification of domestic aggregates and the prevention of alkali-aggregate reaction in concrete used in road pavements and engineering structures (GDDKiA, https://www.gddkia.gov.pl/pl/1118/dokumenty-techniczne, 1-94, 2019)

13. S. Poyet, A. Sellier, B. Capra, et al , Mater. Struct. Constr. 40, 229-239 (2007)

14. M. Cyr, P, Rivard, F. Labrecque, Cem. Concr. Compos. 31, 438-446 (2009)

15. B. J. Wigum, L. T. Pedersen, B. Grelk, J. Lindgård, State-of-the art report: Key parameters influencing the alkali aggregate reaction (SINTEF Building and Infrastructure, 2006)

16. B. M. Pedersen, B. J. Wigum, J. Lindgård, Influence of aggregate particle size on the alkali- silica reaction - a literature review (15th International Conference on AlkaliAggregate Reaction, 2016)

17. D. Joźwiak-Niedźwiedzka, R. Jaskulski, M.A. Glinicki, Materials 9 (4), 224 (2016) 